\title{
The Japanese Society of Hypertension Guidelines for the Management of Hypertension (JSH 2009)
}

T Ogihara, K Kikuchi, H Matsuoka, T Fujita, J Higaki, M Horiuchi, Y Imai, T Imaizumi, S Ito, H Iwao, K Kario, Y Kawano, S Kim-Mitsuyama, G Kimura, H Matsubara, H Matsuura, M Naruse, I Saito, K Shimada, K Shimamoto, H Suzuki, S Takishita, N Tanahashi, T Tsuchihashi, M Uchiyama, S Ueda, H Ueshima, S Umemura, T Ishimitsu and H Rakugi, on behalf of The Japanese Society of Hypertension Committee for Guidelines for the Management of Hypertension

Hypertension Research (2014) 37, 599; doi:10.1038/hr.2014.68; published online 20 March 2014

Correction to: Hypertension Research (2009) 32, 3-107; doi:10.1038/ hr.2008.15, doi:10.1038/hr.2008.10, doi:10.1038/hr.2008.11

In response to the interim report on the Shiga Microalbuminuria Reduction Trial (SMART study), the Japanese Society of Hypertension (JSH) hereby announces revisions to the Japanese Society of Hypertension Guidelines for the Management of Hypertension (JSH2009). The revisions are as follows:
- Reference No. 415 in the English version of the JSH2009 Guidelines be deleted.

- References to the SMART study in Chapter 6, page 47 be deleted.

- References to the SMART study in Chapter 7, page 52 be deleted. 